\title{
Mediastinal neuroendocrine tumour presenting with ECG changes: An unusual ST-Elevation Myocardial Infarction mimic
}

\author{
Andrew J. Borrie, Tammy J. Pegg \\ Cardiology Department, Nelson Hospital, Nelson, New Zealand
}

Received: May 14, 2018

DOI: $10.5430 /$ crim.v5n3p10
Accepted: June 13, 2018

Online Published: June 21, 2018

URL: https://doi.org/10.5430/crim.v5n3p10

\begin{abstract}
A 63-year-old male was referred to the cardiology team with a one month history of progressive chest pain and shortness of breath. This was associated with general decline, weight loss and new heart failure. Emergency Department ECG showed ST elevation throughout the chest leads and blood tests confirmed an elevated troponin. Clinical examination revealed a precordial mass. Bedside echocardiography showed an akinetic anterior wall with infiltration from a mediastinal mass. CT scan demonstrated a large mediastinal mass invading the sternum, ribs and myocardium. Biopsy showed a high grade neuroendocrine tumour of uncertain origin. Despite the need for rapid treatment of ST-Elevation Myocardial Infarction (STEMI), due care needs to be taken to ensure accurate diagnosis.
\end{abstract}

Key Words: ST Elevation Myocardial Infarction, Neuroendocrine tumour, Cardiology, Oncology, Ischaemic heart disease

\section{INTRODUCTION}

Neuroendocrine tumours (NETs) are a heterogeneous group of tumours arising from diverse cell lines that can present with a range of symptoms. This case describes an unusual presentation of a NET which mimicked a ST-elevation Myocardial infarction (STEMI).

\section{Case PResentation}

A 63-year-old male was referred to the cardiology team with a one month history of constant and progressive chest pain and shortness of breath. He had difficulty sleeping as the pain was exacerbated by lying flat. He could walk for less than five minutes on the flat before having to stop due to shortness of breath. This was associated with a general decline over the previous month, four kilogram weight loss and increasing fatigue. Previous medical history included hypertension, stroke and cutaneous lupus erythematosus. His medications were prednisone, hydroxychloroquine, aspirin, atorvastatin and metoprolol. He was an ex-smoker and did not drink alcohol. His family history was unremarkable.

On examination the patient was thin (BMI $19 \mathrm{~kg} / \mathrm{m}^{2}$ ) and appeared uncomfortable with moderate chest pain. He was haemodynamically stable. A chest wall mass was noted which the patient reported was long standing (he had diagnosed as having a "Pidgeon chest" as a child) but thought it may have changed recently (see Figure 1). The patient had signs of heart failure with peripheral oedema, an elevated JVP and signs consistent with a left sided pleural effusion. There was no lymphadenopathy.

*Correspondence: Andrew J. Borrie; Email: Andrew.borrie@gmail.com; Address: 20 Newcome Crescent, Karori, Wellington, New Zealand. 


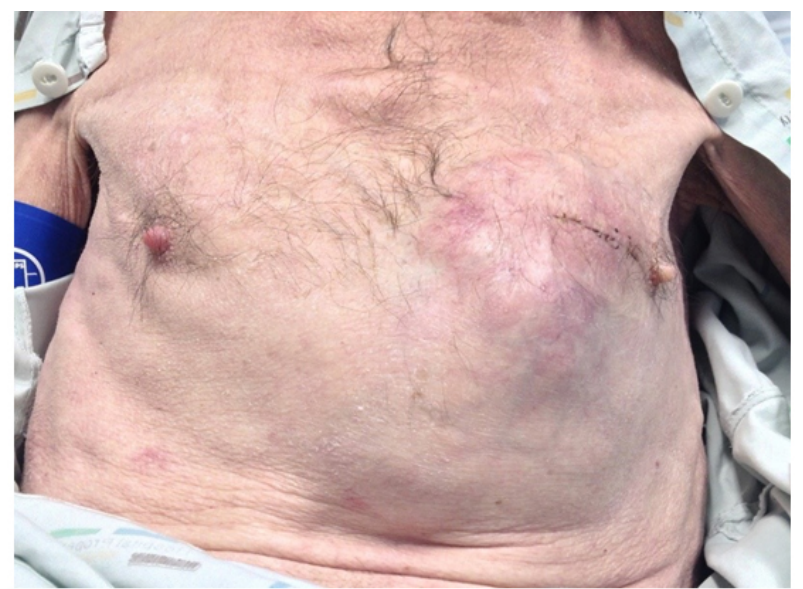

Figure 1. Anterior chest wall mass post biopsy

His ECG showed sinus rhythm with ST elevation throughout chest leads without reciprocal changes. This was new compared with previous ECGs and serial ECGs showed persisting ST elevation rather than evolving changes (see Figure 2).

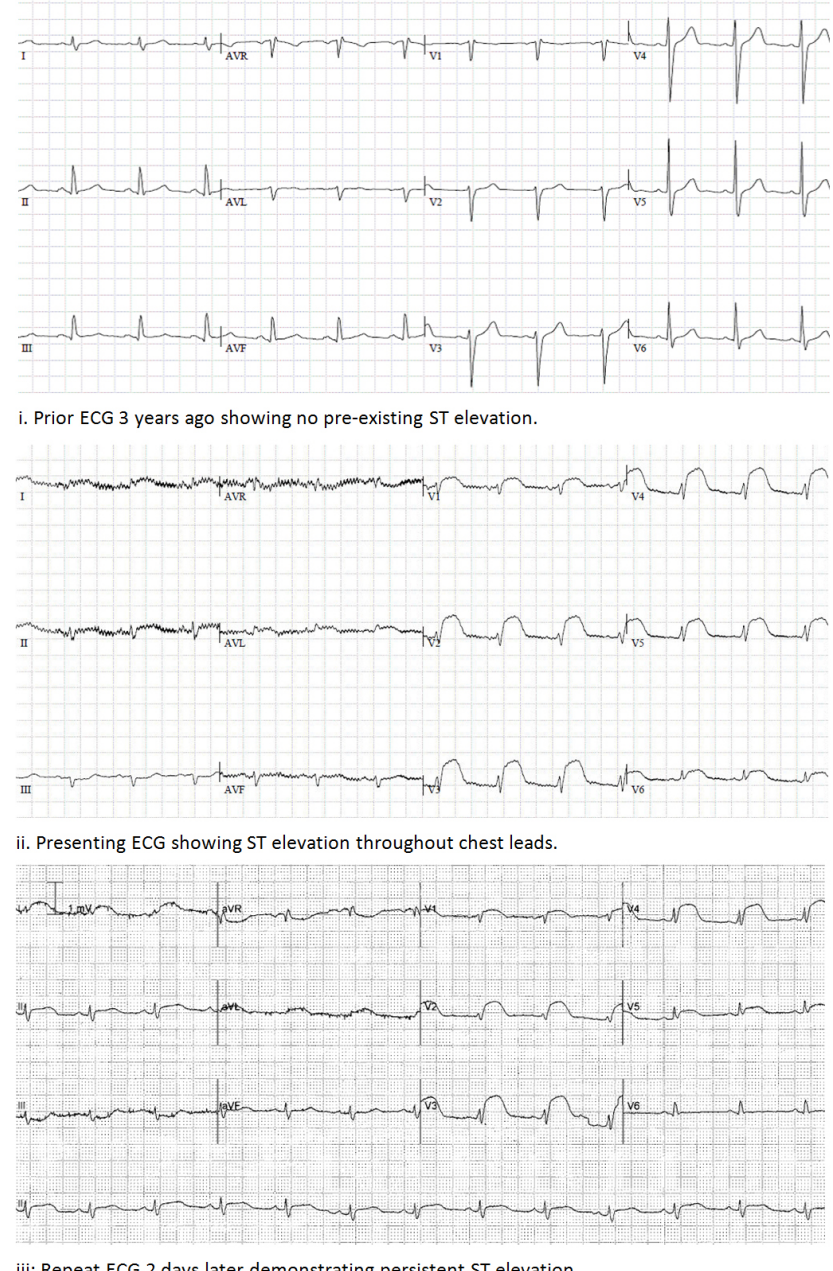

Figure 2. Serial ECGs

Published by Sciedu Press
His chest $\mathrm{x}$-ray showed a large mass in the anteroinferior aspect of the left hemithorax with associated moderate left basal pleural effusion (see Figure 3). Initial high sensitivity troponin T was $298 \mathrm{ng} / \mathrm{L}, 3$ hour troponin was 327 and repeat 12 hours later was 355 . He was anaemic with a haemoglobin of $102 \mathrm{~g} / \mathrm{L}$ and had elevated inflammatory markers with a $\mathrm{C}$ reactive protein of $103 \mathrm{mg} / \mathrm{L}$. His eGFR was $>90 \mathrm{ml} / \mathrm{min}$.

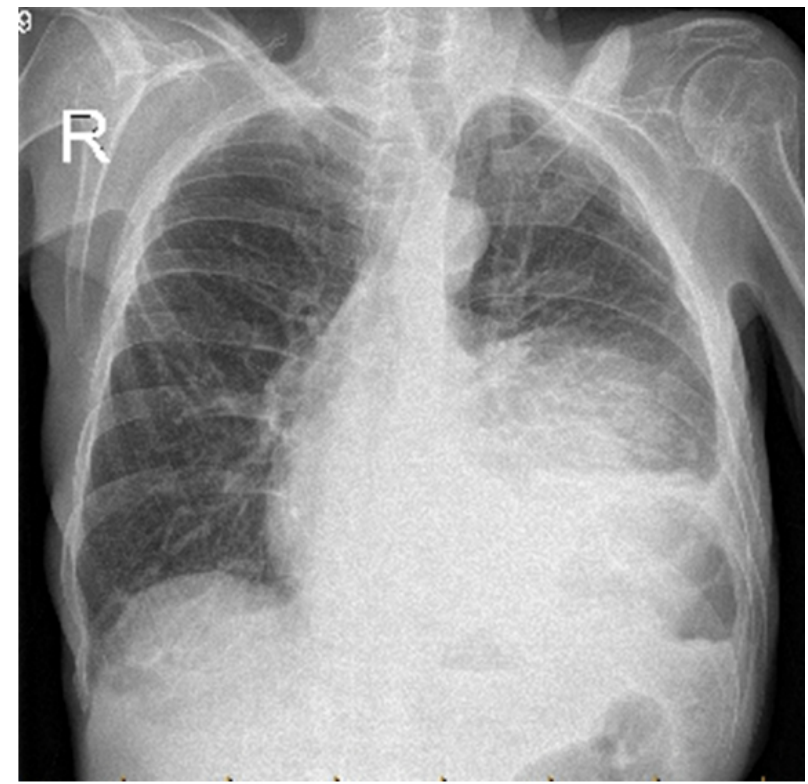

Figure 3. Chest X-ray with mass in anteroinferior aspect of the left hemithorax with associated pleural effusion

The diagnosis of late presentation ST elevation myocardial infarction was considered but given the atypical features the differential diagnosis included myopericarditis and malignancy. The patient was treated in a peripheral hospital where coronary angiography was not available until the following day. Echocardiography showed an akinetic anterior wall with infiltrating chest wall mass adjacent to the anterior wall and right ventricle. There was a small amount of pericardial fluid without features of tamponade. A CT scan was performed to further investigate which showed a $161 \mathrm{~mm}$ anterior mediastinal mass invading the sternum, ribs and anterior myocardium with associated pleural effusion (see Figure 4). There was also a $48 \mathrm{~mm}$ mass in the splenic hilum suspicious for metastatic disease.

The etiology of the patient's presentation was unlikely to be ischaemic (due to tumour disrupting the left anterior descending coronary artery) as his chest pain and ST elevation was constant for over a month and did not resolve. More likely his presentation was related to direct compression and infiltration of myocardium by the tumour causing tissue injury. Therefore an angiogram was not performed as it was felt risks would outweigh benefits. The location of the tumour 
would increase the risk of bleeding while making viable and beneficial interventional targets unlikely.

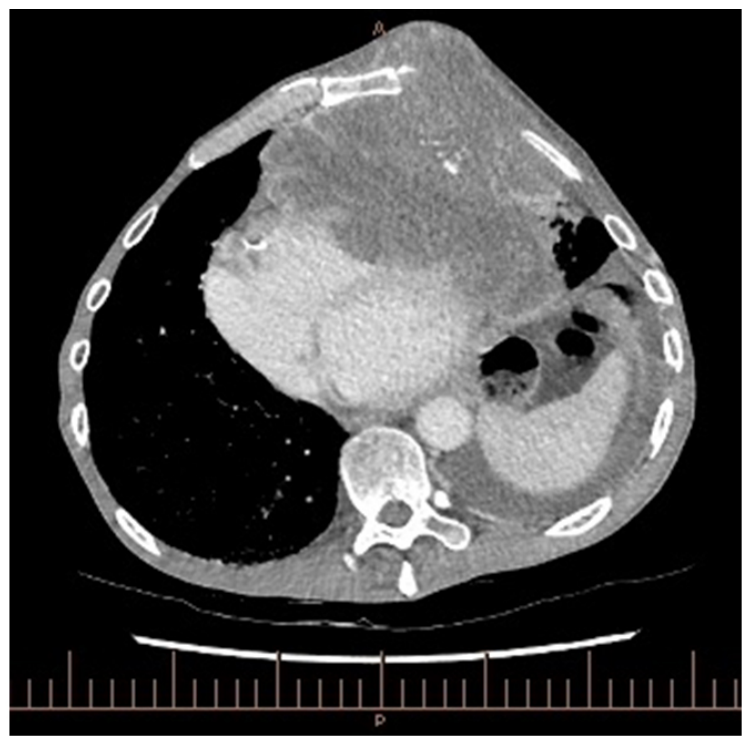

Figure 4. CT scan showing large anterior mediastinal mass invading myocardium

A biopsy was performed which showed a high grade poorly differentiated tumour with necrotic areas, positive for expression of neuroendocrine markers synaptophysin and CD 56, but no carcinoma markers. It was also positive for various other lineage non-specific markers with Ki67 proliferation rate $75 \%$, p53 and c-myc positive, consistent with an aggressive high grade neuroendocrine tumour of uncertain origin Given the tumour's location the tissue of origin was suspected to be thymic.

The patient was referred to oncology and was managed with palliative carboplatin and etoposide chemotherapy and hospice involvement.
Unfortunately he died 2 months later from neutropenic sepsis.

\section{DiscuSSION}

NETs are a heterogenous group of tumours arising from a large variety of cells. The neuroendocrine system includes endocrine glands (such as the pituitary, parathyroid and adrenal glands) as well as endocrine islet tissue (thyroid and pancreas) and scattered cells in exocrine parenchyma in the gastrointestinal and respiratory tract. ${ }^{[1]}$ NETs have been described in the central nervous system, respiratory tract, thyroid, skin, breast and genitourinary system, the most common sites of NETs however are the gastrointestinal tract and lungs. $13 \%$ of NETs are of unknown source. ${ }^{[2]}$ The WHO classifies NETs by differentiation (well differentiated or poorly differentiated) and by tumour grade (assessed by mitotic rate and $\mathrm{Ki}-67$ index). ${ }^{[3]}$ High grade poorly differentiated NETs are generally aggressive tumours but have high response rates to platinum/etoposide chemotherapy. ${ }^{[4]}$

This case is an example of an unusual STEMI mimic. Guidelines recommend rapid assessment of patents with chest pain as mortality in STEMI has been shown to increase with each 15 minute delay to reperfusion. ${ }^{[5]}$ Despite having chest pain, ST elevation and an elevated and rising troponin this presentation did not represent infarction in the usual sense. If this patient had been thrombolysed this would likely have resulted in catastrophic bleeding. While door to needle time is an important target, due care needs to be taken to ensure the correct diagnosis is made and that no contraindications to thrombolysis (or percutaneous intervention) are present.

\section{CONFLicts OF InTEREST Disclosure}

The authors declare no conflicts of interest.

\section{REFERENCES}

[1] Oronsky B, Ma P, Morgensztern D, et al. Nothing But NET: A Review of Neuroendocrine Tumors and Carcinomas. Neoplasia. 2017; 19: 991-1002. PMid:29091800. https://doi.org/10.1016/j.neo. 2017.09 .002

[2] Yao JC, Hassan M, Phan A, et al. One hundred years after "carcinoid": epidemiology of and prognostic factors for neuroendocrine tumors in 35,825 cases in the United States. J Clin Oncol. 2008 26: 3063. PMid:18565894. https://doi.org/10.1200/JC0.20 07.15 .4377
[3] Bosman T, Carneiro F, Hruban RH, et al. WHO Classification of Tumours of the Digestive System, 4th ed, International Agency for Research on cancer (IARC). Lyon. 2010. p.13.

[4] Spigel DR, Hainsworth JD, Greco FA. Neuroendocrine carcinoma of unknown primary site. Semin Oncol. 2009; 36: 52. PMid:19179188. https://doi.org/10.1053/j. seminoncol .2008.10.003

[5] O'Gara PT, Kushner FG, Ascheim DD, et al. ACCF/AHA guideline for the management of ST-elevation myocardial infarction: a report of the American College of Cardiology Foundation/American Heart Association Task Force on Practice Guidelines. Circulation. 2013; 127: e362. https://doi.org/10.1161/CIR.0b013e3182742c84 